\title{
English versus Spanish in science evaluation
}

\author{
Jesús Rey-Rocha, M. José Martín-Sempere \\ Centre for Scientific Information and Documentation (CINDOC). \\ Spanish Research Council (CSIC) \\ Joaquín Costa, 22. 28002 MADRID (SPAIN) \\ e-mail: J.Rey@cindoc.csic.es \\ Fernando López-Vera \\ Department of Agricultural Chemistry, Geology and Geochemistry \\ Faculty of Sciences \\ Autonomous University of Madrid \\ Jesús Martínez-Frías \\ Department of Geology \\ National Museum of Natural Sciences \\ Spanish Research Council (CSIC) \\ This is an author post-print (ie final draft post-refereeing) of the \\ 'scientific correspondence' paper published in Nature, 397 ( 7 january \\ 1999): 14 \\ Sir,
}

Gianmarco Paris et al. ${ }^{1}$ consider how the frequency with which an article is cited is affected by its country of origin. They base their information on the Science Citation Index (SCl), an Institute of Scientific Information service comprising approximately 3,500 of the world's leading scientific and technical journals covering a broad range of disciplines. A parallel problem concerning this excellent database is seriously affecting some European and Latin American countries ${ }^{2}$. This is the misuse of the $\mathrm{SCl}$ in relation to language of publication in certain fields of work that are characterized by territoriality (for example, Earth science).

Major problems with its use can occur when: (1) publication in $\mathrm{SCl}$ journals is used as the only criterion for evaluating the scientific productivity of researchers and when it is used to confer prestige, stipends and even promotion; and (2) scientific tribunals pay more attention to the impact factor of the journal than to the quality of the scientific contribution. Bearing in mind the difficulty of comparing quite similar $\mathrm{CVs}$, the SCl-based evaluation provides an easier judgement procedure. But it is unfair to scientists from countries whose journals are poorly or not represented in the SCl. A good example of this biased analysis has recently been pointed out by the Centre for Scientific Information and Documentation (CINDOC) of the Spanish Consejo Superior de Investigaciones Científicas (CSIC). The CINDOC is responsible for producing and distributing the ICYT database, a set of contributions in science and technology that has covered 500 Spanish bibliographic sources at an average annual rate of 6,500 items since 1979 .

The CINDOC study covers a five-year period, surveying the productivity of the whole Spanish community of Earth scientists, and obtaining the opinion - using a specially created, 27-point survey - of 383 of these researchers ${ }^{3}$. The design of the study allows it to indicate the extent of the language problem, as no Spanish-language Earth science journal is currently included in this $\mathrm{SCl}$ category. The results obtained indicate that, whereas $73 \%$ of these scientists usually publish in both $\mathrm{SCl}$ and Spanish journals, most of their articles (69\%) are published in domestic journals. Therefore, the application of a solely $\mathrm{SCl}$-based evaluation does not properly reflect their total scientific productivity and thus makes them unhappy with this evaluation procedure (58.5\% of the whole, and more than $70 \%$ of researchers from universities and CSIC). When other databases besides the SCI and ICYT are included so as to give a wider range of Earth science journals (for example, GeoRef), 
the Spanish contribution to Earth science is found to be $7.3 \%$ of European production, occupying sixth place after the United Kingdom, France, Germany, Holland and Italy. The corresponding number derived from the $\mathrm{SCl}$ database is $5.6 \%$.

It is true that the lack of publication in $\mathrm{SCl}$ journals can indicate the low quality of some scientific contributions and/or the authors' inability to publish in high-quality international journals. But it is also true that scientific authorities should not disregard the idiosyncratic nature of some research fields, or the difficulty of publishing domestic work in international journals that demand topics be of "general interest". Thus, a frequent answer of journal editors is: "the paper is good but it would fit better in a local or regional journal". They apparently fail to realize that, due to the preponderance of English in science, many English papers are just as domestic as the Spanish ones. However, English-language journals that publish domestic science, such as J. Geol. Soc., Lond., get into the SCl, whereas the equivalent Spanish-language journals, such as Rev. Soc. Geol. Esp., do not.

If Europe wants a strongly united scientific community, it should define evaluation criteria that do not undervalue the quality of a publication simply because it is written in the 'wrong' language.

\section{References:}

1. Paris, G.; De Leo, G.; Menozzi, P.; Gatto, M. . Region-based citation bias in science. Nature 396, (1998)

2. García-Guinea, J. Two sides of Spanish science. Nature 379, (1996), p. 109.

3. Rey-Rocha, J. La investigación en Ciencias de la Tierra en el marco del Sistema Español de Evaluación Científica: estudio bibliométrico. Tesis Doctoral. Universidad Autónoma de Madrid.(1998). 